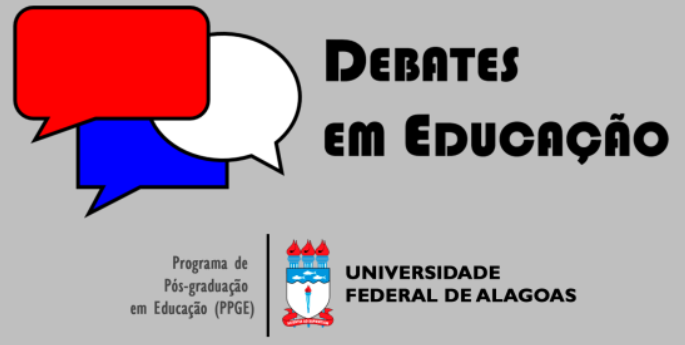

ISSN Eletrônico 2175-6600

Vol. 10 | №. 22 | Set./Dez. | 2018

Maria Auxiliadora Soares Padilha 9 iD

Universidade Federal de Pernambuco (UFPE) dorapadilha@gmail.com

\section{INCLUSÃO DIGITAL COMO DIREITO HUMANO: A ESCOLA, SEUS SUJEITOS, SEUS DIREITOS}

\section{RESUMO}

O artigo discute a inclusão digital em escolas públicas, na perspectiva do direito humano do aluno e da importância de professores e gestores nesse processo inclusivo. Levantamos os dados deste estudo através de entrevistas semiestruturadas com alunos e professores. A inclusão digital é um direito humano que deriva seus direitos humanos de um novo movimento social provocado pela inserção das tecnologias digitais em todos os espaços vitais para a sobrevivência em nosso planeta.

Palavras-chave: Inclusão Digital. Direito Humano. Escola.

\section{DIGITAL INCLUSION AS HUMAN RIGHTS: THE SCHOOL, ITS SUBJECTS, ITS RIGHTS}

\begin{abstract}
The article discusses the digital inclusion in public schools, from the perspective of the human right of the student and the importance of teachers and managers in this inclusive process. We collected data from this study through semi-structured interviews with students and teachers. Digital inclusion is a human right that derives its human rights from a new social movement caused by the insertion of digital technologies in all the spaces vital for the survival on our planet.
\end{abstract}

Keywords: Digital Inclusion. Human Right. School.

Submetido em: 02/07/2018

Aceito em: 21/10/2018

Publicado em: 21/12/2018

DOI: 10.28998/2175-6600.2018v10n22p191-204 


\section{INTRODUÇÃO}

Este artigo tem como objetivo discutir a inclusão digital nas escolas públicas, na perspectiva do direito humano do aluno e da importância dos professores e gestores nesse processo inclusivo. Essa discussão vem-se tornando cada vez mais necessária, se considerarmos a constante e crescente inserção de tecnologias digitais nas redes públicas de ensino, seja via programas federais, estaduais ou municipais.

Tablets, notebooks, lousas digitais, portais e repositórios de materiais e conteúdos digitais, ambientes virtuais de aprendizagem, entre outras tantas novidades adentram 0 ambiente escolar de uma forma avassaladora e com um investimento financeiro que não se via há tempos, nas redes públicas de ensino. Nesse contexto, vemos escolas com infraestrutura modelo e outras sucateadas, com paredes remendadas, funcionando em prédios alugados e (mal)adaptados; escolas urbanas e rurais; todas elas, estão recebendo esses investimentos, com a finalidade de que possam inovar e incrementar o processo educativo.

Apesar disso, observamos que mesmo com tanto investimento, ainda é muito precária a utilização de recursos didáticos-tecnológicos, especialmente os digitais, nas salas de aula do ensino fundamental, em escolas públicas (PADILHA; ABRANCHES, 2010; PADILHA; ABRANCHES, 2013a). Além disso, os professores nem sempre recebem formação para usar pedagogicamente esses recursos e ainda há uma grande dificuldade com a manutenção desses equipamentos nas escolas.

Por vezes, tomamos conhecimento de atividades esporádicas, de alguns poucos professores inovadores. Contudo, essa não tem sido uma prática constante e, mesmo assim, essas práticas são isoladas e carecem de maior integração com os demais professores, não somente na própria escola, mas também em toda a rede.

Essa prática isolada e ainda rara é resultado também de uma incompreensão, por parte de muitos professores e gestores, de que usar tecnologia na sala de aula hoje não é mais opção para o professor ou para a escola. Os alunos precisam ter acesso às diversas linguagens, inclusive e, principalmente, as digitais, pois vivem em um mundo digital e não podem ser alijados desse processo. Mas essa apropriação deve ser crítica, consciente e criativa. Por isso, é fundamental compreender a inclusão digital dos alunos das escolas públicas e de qualquer criança e adolescente, como um direito humano, imprescindível para sua vida na sociedade atual.

Nessa conjuntura da escola pública, podemos observar pelo menos, três pontos de vista: (1) alunos ávidos por acederem a esses dispositivos tecnológicos que, na maioria das 
vezes, não estão ao seu alcance; (2) professores com perspectivas de uso didático bastante diferenciados, que vão da resistência ao deslumbramento e; (3) gestores escolares, que gerem uma escola baseada em um modelo tradicional e burocrático, mesmo vivendo num contexto de novas demandas educacionais, culturais e sociais.

Além desses atores também poderíamos analisar outros pontos de vista, como os pais e a família, a gestão pública das redes, a comunidade, entre outros. Entretanto, iremos focar nosso estudo nos três primeiros citados, tendo em vista que são os segmentos com os quais trabalhamos em nossos estudos até o momento.

Levantamos as expectativas e interesses de jovens em usar tecnologias digitais através de entrevistas semiestruturadas com alunos de uma escola pública, participantes de oficinas realizadas através do Programa de Extensão Proi-Digital: espaço de criação para inclusão digital de jovens da periferia de Recife, Olinda e Caruaru, desenvolvido pela Universidade Federal de Pernambuco e aprovado pelos Editais do Ministério da Educação/Secretaria de Ensino Superior do Brasil 2010, 2011, 2012 e 2013.

As compreensões dos professores e gestores foram identificadas através de entrevistas semiestruturadas com esses atores em duas escolas públicas estaduais de Pernambuco.

Nesse estudo, identificamos a visão que esses atores (alunos, professores e gestores) possuem da inclusão de tecnologias na escola, e analisamos esses resultados do ponto de vista do direito do aluno ao acesso e uso de tecnologias digitais. Cada um desses levantamentos foi identificado como estudos, separadamente, e a descrição da pesquisa e seus resultados serão apresentados juntamente com a fundamentação teórica para tal. Por fim, discutimos esses resultados em conjunto, considerando a relação entre eles e o direito humano do aluno de ser incluído digital.

Por ter o objetivo de compreender a problemática da inclusão digital como direito humano, presente no campo social, esse estudo se identifica como uma pesquisa qualitativa que, segundo Laville e Dione (1999, p. 43), significa "conhecer as motivações, as representações, considerando os valores, mesmo se dificilmente quantificáveis".

\section{JOVENS, CULTURA E TECNOLOGIAS DIGITAIS}

Inúmeras discussões sobre questões contemporâneas são apresentadas atualmente levando em consideração o contexto cultural e as relações sociais, econômicas e políticas que tecem as redes afetivas e cognitivas do conhecimento no que tange à relação entre tecnologia e educação. Nessas discussões, um dos grupos sociais mais 
analisados é o de jovens, no entanto, ao mesmo tempo em que eles são a maioria dos integrantes que compõem a cultura digital, nem sempre são considerados incluídos digitais aos olhos de muitos autores (ANDRADE, 2012; CAZELOTO, 2008), nem mesmo no sentido simples do mero acesso à tecnologia.

A cultura digital é própria da geração internet, exige a capacidade de lidar com vários ambientes de informação e propõe novos hábitos, práticas e relações sociais em torno das tecnologias digitais e da emergência comunicacional na contemporaneidade. Nesse contexto, os jovens são os mais propensos a aderir a essa cultura, até mesmo porque são contemporâneos a elas. Na verdade, eles são constituídos e constituem, ao mesmo tempo, essa cultura digital, pois a alimentam e se nutrem de suas inovações e práticas.

Em seu dia a dia, os jovens estão conectados. Independentemente de sua classe social, etnia ou nacionalidade estão produzindo, compartilhando, remixando e colaborando com a rede de interconexões dessa cultura planetária. Com a mesma velocidade e voluptuosidade eles reproduzem, copiam e burlam as poucas fronteiras existentes na rede. Essa vivência digital pode ser individual, compartilhada e colaborativa.

Segundo López e Samek (2011, p. 22), "estamos na eminência de um novo direito a partir do ambiente tecnológico criado no mundo da informação e comunicação". Isso ocorre por conta da influência das tecnologias nas mais diversas ações da humanidade para poder viver neste mundo com dignidade e qualidade.

É necessário considerar, contudo, que esse acesso é diferenciado. Jovens de classes populares possuem os dispositivos, estão na rede, produzem e compartilham, mas com menos recursos materiais e até mesmo referenciais e dispositivos obsoletos. Não se pode negar também que o convívio social e as experiências culturais influenciam na constituição dos sujeitos, em sua profissionalização e nas condições e oportunidades que surgem em sua vida.

Isso implica uma brecha digital que promove um distanciamento cada vez maior entre as camadas sociais da população, gerando oportunidades desiguais e situações de vida cada vez mais desumanizantes para as pessoas mais pobres. Nesse sentido, Cerveró et al. (2011, p. 87) afirmam que "este processo exige um tratamento que leve a superação de situações de desigualdade, por meio da formação da cidadania em competências informacionais e tornando o uso da tecnologia acessível a todas as pessoas".

Analisando a inclusão digital como um aspecto, dentre outros, necessários para a inclusão social dos sujeitos, este estudo buscou respostas nas atividades com jovens de um Programa de Extensão que visa contribuir para a construção de uma rede de aprendizagem colaborativa, através da interpretação, produção e compartilhamento de 
conteúdos digitais, que se expressam em oficinas de animação - vídeo, áudio digital e blog - com jovens de periferia das cidades de Recife e Olinda, no Brasil. Os espaços de realização das oficinas desse programa são: a própria universidade, eventos acadêmicos, bibliotecas e escolas públicas.

Essas oficinas visam proporcionar uma visão crítica, criativa, interpretativa e produtiva de materiais digitais, com vistas à inclusão dos jovens no mundo da produção digital e, assim, colaborar para uma maior inserção digital desses. Além disso, as oficinas pretendem incentivar os participantes a promoverem novas oficinas para outros jovens da comunidade.

Os dados desse estudo foram coletados na realização das oficinas do Programa de Extensão em uma escola de Recife, com crianças e jovens do $8^{\circ}$ e $9^{\circ}$ ano do Ensino Fundamental. Responderam a uma entrevista semiestruturada dezoito (18) jovens estudantes da escola, com idades entre doze (12) a dezesseis (16) anos, que realizaram as oficinas de blog, animação, áudio e vídeo.

Todos os participantes das oficinas são usuários da Internet e de redes sociais, além de acessarem a internet quase todos os dias da semana. O local onde acessam a internet é, segundo eles, em casa e na escola: sete (7); na lan house: oito (8); na casa de parentes e amigos: cinco (5) e; pelo celular: três (3). Os jovens puderam responder mais de uma opção de acesso.

A maior preocupação em participar de um projeto como esse, para os alunos, é: a qualificação profissional, oito (8); para usar a internet, um (1); para aprender a criar texto, vídeos, ou áudio usando o computador, sete (7); para aprender a usar o computador, dois (2) e; para melhorar seu desempenho na escola apenas um (1).

Observamos, portanto, a grande intimidade dos alunos com os dispositivos digitais e a internet, considerando que as principais preocupações são a empregabilidade e a inserção pessoal no mundo digital. Isso revela uma grande preocupação dos jovens em estarem habilitados a viver no mundo, adquirindo habilidades necessárias para essa inserção no mundo do trabalho. Ao mesmo tempo, os jovens sentem a necessidade de inserção no mundo digital para aprender e criar conteúdos digitais que, sem dúvida, são o caminho para a sua socialização no mundo digital. Eles querem fazer parte desse movimento social, que tem como locus o espaço da cibercultura que, segundo Lévy (1999, p. 124), por sua vez provoca "um tipo particular de relação entre as pessoas".

Para o autor (idem, p. 126), esse movimento social se estabelece no "ciberespaço como prática de comunicação interativa, recíproca, comunitária e intercomunitária o 
ciberespaço como horizonte de um mundo virtual vivo, heterogêneo e intotalizável no qual cada ser humano pode participar e contribuir".

Para esses jovens, estar incluído digitalmente é: incluir todos na rede de computadores"; "poder saber mexer nos computadores para usar na escola"; "é ter acesso ao computador para no futuro encontrar um trabalho"; "é se qualificar para uma profissão" e também "é direito de todos ter acesso ao computador" (Respostas dos jovens alunos das oficinas).

É necessário, contudo, superar a relação acesso-inclusão. Consideramos que inclusão digital não é apenas ter acesso a recursos digitais, mas compreendê-los, interpretá-los, produzi-los e compartilhá-los, seguindo uma cadeia de aprendizagem de novas linguagens midiáticas. Isso significa saber usá-los em seu benefício e do coletivo (PADILHA, ABRANCHES, 2013b).

O pouco interesse em realizar atividades escolares com esses recursos (apenas um aluno citou essa possibilidade) mostra uma evidente falta de integração das tecnologias na escola. Considerando que essa instituição é o principal veículo de inclusão digital (SORJ; GUEDES, 2005) faz sentido afirmar que ela não está cumprindo o seu papel social de incluir seus alunos. Segundo Haddad (2004, p. 3):

Conceber a Educação como Direito Humano diz respeito a considerar o ser humano na sua vocação ontológica de querer "ser mais", diferentemente dos outros seres vivos, buscando superar sua condição de existência do mundo. Para tanto, utilizase do seu trabalho, transforma a natureza, convive em sociedade.

Nesse sentido, para que a educação exerça seu papel de contribuir para a formação dessa vocação dos sujeitos e, considerando que a escola não é o único espaço educativo na vida desses sujeitos, ela deve estar atenta aos novos locus de relações e movimentos sociais que fomentam novas formas de aprender e ensinar.

\section{ESCOLAS, PROFESSORES E GESTORES ANALÓGICOS VS ALUNOS DIGITAIS}

Prensky (2012), em 2001, cunhou os termos 'nativos digitais' e 'imigrantes digitais' definindo as diferenças entre os que nasceram na era digital e, portanto, são contemporâneos às mais avançadas tecnologias da informação e comunicação e os que estavam aprendendo a lidar com essas tecnologias em um tempo diferente, com formas e compreensões anteriores à era de então. 
O próprio autor afirma que essa distinção, hoje, é cada vez mais desnecessária no mundo atual (PRENSKY, 2012). Porém, na escola que temos hoje ainda percebemos alguns problemas na integração das tecnologias na educação, que denotam uma clara distinção de atitude, entre alunos e professores, frente às tecnologias digitais, a saber.

- A escola é uma instituição mais tradicional que inovadora. Mesmo com grande investimento em recursos didáticos, a inovação permanece no nível tecnológico, não chegando ao pedagógico, tendo em vista que grande parte dos professores não consegue integrar as tecnologias a seu fazer docente e aos objetivos educacionais da sala de aula e da escola como um todo.

- Os modelos de ensino focados no professor continuam predominando, apesar dos avanços teóricos em busca de mudanças do foco do ensino para o de aprendizagem. Para usar tecnologias para aprender de forma criativa, crítica, democrática e colaborativa é preciso estabelecer estratégias focadas na aprendizagem do aluno, diferentemente de uma abordagem tradicional, onde o foco é o ensino.

- Muitos professores têm medo de revelar sua dificuldade com as tecnologias diante do aluno. Por isso, e também pelo hábito de uma prática conservadora, mantêm uma docência repressiva, controladora, repetitiva.

- Os gestores (das escolas e das redes) se frustram ao ver que tanto esforço e dinheiro investidos não se traduzem em mudanças significativas nas aulas e nas atitudes do corpo docente.

Vemos, portanto, que quase nada mudou na escola com a introdução de tantos recursos didáticos tecnológicos. A pouca experiência dos professores com tecnologias digitais e, mais complicado ainda, a grande resistência de muitos deles, em utilizar as tecnologias em sala de aula, demonstra uma enorme diferença em relação à cultura digital dos alunos e a cultura digital dos professores. Isso é um entrave à introdução das tecnologias em sala de aula que deve ser discutido e combatido com formação continuada, mas também com uma postura mais aberta às inovações pedagógicas por parte dos professores.

Observa-se que os professores até se apropriam dessas tecnologias em seu dia a dia para se comunicar, se informar, pesquisar e também para seu lazer. Entretanto, não conseguem que sua cultura digital social se transforme em uma cultura digital pedagógica.

Padilha e Abranches (2013a) afirmam, a partir de dados de um processo de formação continuada de professores do ensino fundamental que, em sua maioria, os professores compreendem a utilidade da tecnologia no seu cotidiano social e ressaltam o seu caráter inovador e a importância de usá-la, também, na educação. Os professores 
reconhecem o potencial pedagógico da tecnologia e, ao serem questionados, na formação citada, sobre as possibilidades pedagógicas dos recursos didáticos tecnológicos informam que estes podem ser utilizados para pesquisas, leituras, atividades diversas. Além disso, os professores constatam o poder motivacional e dinamizador das tecnologias na sala de aula. Contudo, os autores relatam que, na hora de planejar as aprendizagens de seus alunos com essas tecnologias, os professores, em geral, mantêm uma prática tradicional. A esse respeito, diz Alonso (2003, pp. 25-26):

No que diz respeito ao gestor escolar, observa-se que a introdução das tecnologias digitais iniciou pela secretaria da escola, utilizada com fins burocráticos para organização das atividades administrativas. A base estrutural da escola, hoje, ainda é "o modelo burocrático de concepção funcionalista, faiolista, com ênfase na produção, aqui entendida como acumulação de 'conhecimentos' (entenda-se informações/reproduções); fechada para o meio exterior, não estabelece trocas com ele".

Diante do contexto atual, a escola deveria repensar sua finalidade e, se por um lado algumas concepções mudam dentro da escola de forma muito lenta, por outro lado, fora da escola as transformações são céleres. Isso amplia, cada vez mais, o descompasso entre a escola e as necessidades reais dos alunos e da sociedade. Assim como os professores, os gestores também necessitam de formação continuada para compreender essas transformações, os desafios postos para a escola e as formas de como responder a esses desafios que são tanto administrativos como pedagógicos. Segundo Alonso (2003, p. 30):

Compreender as tarefas administrativas a partir do trabalho pedagógico, de suas exigências e das novas demandas educacionais é condição fundamental para que se redirecione o fazer administrativo, de modo a facilitar a introdução das mudanças necessárias na prática docente e no desenvolvimento das propostas pedagógicas.

Por esse motivo, entrevistamos gestores e professores de duas escolas públicas do estado de Pernambuco, Brasil, objetivando entender qual a contribuição das tecnologias na escola, em sua visão, e qual o papel do gestor na introdução destas no cotidiano escolar. Realizamos entrevistas semiestruturadas com dois gestores e dois professores de cada escola.

Assim como o relatório de Padilha e Abranches (2013a) todos os sujeitos concordaram que as tecnologias são importantes para a educação e que devem fazer parte dos recursos utilizados na escola. Dois professores afirmam que, com as tecnologias, os professores não são mais as únicas referências de saberes para os alunos. E um gestor diz que é preciso orientar os alunos para usar as tecnologias.

Se forem usadas da maneira correta sim, agora se os alunos não forem orientados para usar, não adianta de nada, porque se eles vão usar da maneira que eles querem, não da maneira que a gente quer que eles absorvam as coisas... apesar 
que a gente também não pode querer que 0 aluno tenha a ótica que a gente tem, mas que ele passe a criar a partir dali (Gestor da escola 2).

Algo que realmente vale a pena comentar é a preocupação dos professores e gestores com o que o aluno está fazendo com e nesses novos espaços de socialização. Claro que é necessário que o professor oriente o aluno para uma utilização consciente e crítica dos recursos digitais. Entretanto, o que vemos mesmo é a preocupação do professor com a falta de controle que ele possui, do aluno e do que ele está fazendo e aprendendo, sem a sua vigilância e determinação do que ele pode ou não vir a conhecer, e como isso ocorrerá.

Sobre o papel do gestor na introdução das tecnologias na escola, os professores afirmam que ele é fundamental, mas também reconhecem seu papel nesse processo.

Eu acredito que ajuda bastante. Acho... assim... muita coisa parte da gente no final das contas. A gente tem que trazer muitas coisas, mas eu acredito que a escola tem essa capacidade de ajudar, seja com os recursos de internet... aqui a gente tem um laboratório de informática que o professor pode utilizar, temos alguns outros recursos de mídia... aqui eles facilitam bastante (Professor 1 da escola B).

No que se refere à introdução de tecnologia na escola, professores e gestores reconhecem o investimento das redes em incrementar a escola de recursos tecnológicos. Mas também sabem que isso não acontece em todas as escolas. Além disso, eles se ressentem de que, apesar de a escola estar mudando, aparentemente, a sala de aula não está. Diz um dos professores

Aqui no nosso Estado, por exemplo, se falando da rede estadual, diferentes lugares,
as escolas estão esquecidas. Então não tem condições de trabalhar com
ferramentas oferecidas, as escolas de bairros pobres são muito esquecidas. O
governo oferece muitas coisas, hoje com certeza a questão da tecnologia tá
modificando as escolas, agora temos que pensar também na sala de aula, não a
escola como um todo, mas a sala de aula. Como está acontecendo a aula na sala
de aula? A gente tem que pensar como responder essa pergunta, como é que está
ocorrendo a aula, porque ter o suporte e a aula não fluir não adianta (Professor 2
da escola B).

É importante que o professor reflita sobre sua prática, desvencilhando-se de ações reprodutivistas, rompendo com concepções ultrapassadas e buscando ousar, inovando e articulando os saberes teóricos, que já defendem na teoria, e colocando-os em prática, numa ação consciente e competente. Garcia (2012, p. 242) afirma que, independente do nosso "colete ideológico" devemos sempre agir a partir de uma prática educativa crítica e reflexiva. Para ele (idem, p. 243), nós, professores estamos:

[...] ou engessados em práticas rotineiras, baseadas fundamentalmente em modelos transmissivos, [pois] não soubemos romper com os princípios didáticos e organizativos que nos dão segurança e proteção, [...] ou abraçamos o messianismo tecnológico proclamando hosanas integrados a essa tecnologia redentora, 
realizando adaptações adocicadas de nossas velhas metodologias, nessa velha e cíclica tentativa de mudar tudo para que nada mude, pedagogias prêt-a-porter, com conexão à internet einclusive uso de plataforma.

Nesse sentido, em que medida a introdução dessas tecnologias na escola está modificando não somente a prática desses professores, mas, principalmente a vida dos alunos e suas famílias? Até que ponto a inclusão digital, proclamada pela mídia política (ou politiqueira) dos governos (bem ou mal) intencionados realmente supera uma visão mercantilista, da preparação para a empregabilidade, e se torna uma possibilidade (ibidem),

[...] de libertação para encontrar novos significados e novas ideias para a ação social organizada, através de uma pedagogia do questionamento que supere a superabundância de informação em conhecimento epistemologicamente válido e socialmente relevante?

É bem verdade que, para que os professores tenham a condição de estimular essa possibilidade, eles precisam se atualizar e compreender bem o potencial dessas tecnologias para ensinar e aprender. Mas não há uma relação direta entre aprendizagem e tecnologias. É necessário que o professor realize a mediação dessa relação e estabeleça estratégias de aprendizagens significativas com o uso desses recursos. E, para isso, é necessário o investimento em formação continuada, mas, esse investimento também tem que vir em forma de condições para a formação. E o gestor escolar é fundamental nesse sentido. Contudo, rever as condições de trabalho do professor é preciso, visto que os professores não têm tempo para estudar, planejar e organizar sua prática, como podemos ver na fala do professor abaixo.

E aí é difícil porque professores que têm carga horária forte, de manhã, de tarde e as vezes à noite fica difícil. Eu não sei como eles conseguem, eu consigo sem problema, mas professores que tem carga horária completa, de manhã, de tarde e de noite para suprir alguma coisa, não consegue não. Muito boa vontade de fazer uma área tecnológica tem e o próprio alunado hoje, a gente tem que ter algo mais incentivador (Professor 1 da escola A).

Sabemos que a realidade dos professores de ensino fundamental no Brasil, hoje, é muito difícil. Trabalham, em geral, dois turnos e até três, como o professor falou acima e não possuem incentivos para formação e nem mesmo salários adequados às suas necessidades e às suas atividades profissionais. Trabalhar integrando a tecnologia em suas aulas demanda tempo para conhecer os recursos, explorá-los, experimentá-los, estudá-los e planejar estratégias didáticas interessantes e apropriadas aos objetivos de aprendizagem dos alunos.

Como os professores não conseguem tempo e condições formativas para isso, acabam ou rejeitando ou aderindo à tecnologia para apenas continuar fazendo com outros recursos as mesmas coisas que faziam antes. Dessa forma, a lógica do digital, de 
compartilhamento, interatividade, produção criativa e coletiva não é explorada e, assim, o professor age analogicamente mesmo com recursos digitais, promovendo ainda mais o distanciamento do aluno das atividades escolares. Porque assim, o professor consegue fazer ficarem chatos até os mais interessantes recursos digitais.

\section{CONSIDERAÇÕES FINAIS: TECNOLOGIAS NA ESCOLA: INCLUSÃO DIGITAL COMO DIREITO HUMANO}

Não se pode negar que a inclusão digital é condição fundamental para viver e ser cidadão na sociedade hoje. Brandão (2010, p. 13) afirma que o acesso às tecnologias da informação e comunicação pode favorecer à construção de uma sociedade mais justa e igualitária. Segundo ele "um dos aspectos nos quais esse princípio se sustenta é justamente a existência de uma sociedade cujo modo de operação, relações humanas e subsistência se baseiam na informação advinda, sobretudo, da internet".

Para Demo (1995), a cidadania é a raiz dos direitos humanos. Mas, o que significa ser incluído digital e qual a relação dessa inclusão com os direitos humanos?

Incluir não é algo que se realiza de dentro para fora. Na verdade, acreditamos que não se inclui o outro. Inclusão é uma questão de opção. As pessoas devem ter a opção de escolher se querem ou não fazer parte de um determinado espaço ou situação. Uma pessoa pode não ter um celular, por exemplo, não porque ela não tem condições de comprá-lo, mas porque não deseja. A condição para é que dá a possibilidade das pessoas optarem se querem ter ou não um celular, se querem participar ou não de um determinado grupo. Se eu não tenho condição para optar, estou excluído. Segundo Padilha e Santana (2015, p. 6),

\footnotetext{
Um sujeito que tem a condição para optar é um sujeito emancipado. Por emancipação entendemos não apenas o esclarecimento da realidade, mas a condição (econômica, instrumental, cognitiva, cultura e comunicativa ou interativa) para agir nessa realidade.
}

Portanto, ser incluído é ter condições para optar. Essas condições que permitem ao sujeito a opção de estar ou não incluído em uma determinada situação depende da efetivação de seus direitos de cidadão. Para Herrera Flores (2000) deve-se entender por direitos humanos a luta pela libertação humana em busca de uma prática emancipatória. López e Samek (2011 pp. 22-23) afirmam que: maneira violação em seus direitos ao não desfrutar de um nível de vida "adequado" 
(artigo 25 da Declaração Universal de Direitos Humanos), ao menos no sentido de sofre exclusão se não tem acesso à informação e a cultura, que inevitavelmente passa pelo uso das tecnologias da informação e comunicação-

Entretanto, o acesso e o conhecimento instrumental dos recursos tecnológicos não são suficientes para ser incluído digital. Uma das condições necessárias, e fundamentais para a concretização desse processo é a condição cognitiva. Padilha e Santana (2015, p. 8) afirmam que:

é necessário que os sujeitos possuam as condições cognitivas para ser um letrado digital. Isso significa ler, interpretar, compreender e saber argumentar e produzir em qualquer linguagem midiática. (...) compreender o mundo digital é requisito para agir com dignidade e emancipação. Mas, para compreender o mundo atual é preciso decifrar as linguagens digitais.

Quando professores e gestores não se esforçam ou não possuem as condições necessárias, seja de infraestrutura, pedagógicas ou formativas, para usar essas tecnologias digitais com seus alunos de forma competente e emancipatória, como nos fala Garcia (2011), eles estão excluindo seus alunos de uma vida mais digna e, assim, estão violando os seus direitos humanos.

A inclusão digital, portanto, é um direito humano que deriva da nova organização e movimento social (LÉVY, 1999) provocado pela inserção das tecnologias digitais em todos os espaços vitais para a sobrevivência em nosso planeta. Isso significa também acesso à internet. Tecnologias digitais sem conexão com a internet são como um corpo sem alma. Por isso, a escola precisa ter uma conexão adequada às necessidades pedagógicas e pessoais de seus alunos e professores, pois prover as condições para a inclusão do aluno não é somente usar os recursos digitais para 'aprender algo', pois todas as pessoas têm interesses pessoais ao usar a internet, que devem ser respeitados.

Esses interesses referem-se a uma condição subjetiva que está relacionada à forma como esses sujeitos vêm o mundo e se relacionam com eles; com seu meio social e suas experiências na vida. O papel da escola, nesse sentido, é acompanhar e orientar as escolhas e os caminhos navegados e a navegar, fornecendo as condições necessárias para que o sujeito seja emancipado, consciente, crítico e criativo nesse novo ambiente tecnológico e informacional em que vivemos.

\section{REFERÊNCIAS}

ALONSO, M. A gestão/administração educacional no contexto da atualidade. Em Vieira, A. T.; Almeida, M. E. B. de e Alonso, M. Gestão educacional e tecnologia. São Paulo: Avercamp, 2003. 
ANDRADE, M. H. M. DE; SILVA, E. M. DOS S.; PADILHA, M. A. S.; FARIAS, R. Ser autor é se incluir?: Criação de vídeos digitais com jovens de periferia. In: $\mathbf{X}$ Congresso Internacional de Tecnologia na Educação. Recife: Senac, 2012.

BRANDÃO, M. Dimensões da inclusão digital. São Paulo: All Print Editora, 2010.

CAZELOTO, E. Inclusão digital: uma visão crítica. São Paulo: Ed. Senac, 2008.

CERVERÓ, A. C.; MORENO, M. A. G.; LÓPEZ, P. L. e GONZÁLEZ, I. V. Indicadores de inclusão digital e informacional direcionado à saúde: desenvolvimento de competências. In: CUERVAS, A. e SIMEÃO, E. (Orgs.). Alfabetização informacional e inclusão digital: modelo de infoinclusão social. Brasília: Thesaurus, 2011,

DEMO, P. Cidadania tutelada e cidadania assistida. Campinas: Autores Associados, 1995.

GARCÍA, R. I. C. TICs: entre o messiamismo e o prognatismo pedagógico. Em APARICI, R. (Coord.). Conectados no ciberespaço. São Paulo: Paulinas, 2012.

HADDAD, S. O direito à educação no Brasil - Relatoria Nacional para o Direito Humano à Educação. São Paulo: DHESC-Brasil, 2004.

HERRERA FLORES, J. El vuelo de Anteo: derechos humanos y critica de la razón liberal. Bilbao: Desclée de Brouwer, 2000.

LAVILLE, C e DIONNE, J. A construção do saber: manual de metodologia de pesquisa em ciências humanas. Porto Alegres: Editora UFMG: Artmed, 1999.

LÉVY, P. Cibercultura. São Paulo: Editora 34, 1999.

LÓPEZ, P. L. e SAMEK, T. Inclusão digital: um novo direito humano. In: CUERVAS, A.; SIMEÃO, E. (Orgs.). Alfabetização informacional e inclusão digital: modelo de infoinclusão social. Brasília: Thesaurus, 2011.

PADILHA, M. A. S. e ABRANCHES, S. P. Pesquisando e aprendendo sobre o uso das tecnologias da informação e comunicação como recurso didático-pedagógico para o ensino nas escolas da rede pública de ensino fundamental e médio. Relatório de Projeto de Extensão. PROEXT: Universidade Federal de Pernambuco, 2010.

PADILHA, M. A. S. e ABRANCHES, S. P. Proi-digit@I: espaço de criação e compartilhamento para inclusão digital de jovens da periferia de Recife, Olinda e Caruaru. In: CARVALHO, L. M. T. L.; MONTEIRO, C. E. F. Extensão e Educação: experiências formativas, socializantes e inclusivas. Recife: Editora Universitária da UFPE, 2013a.

PADILHA, M. A. S. e ABRANCHES, S. P. Relatório de Formação Continuada na Rede Municipal de Camaragibe. Rede Nacional de Formação de Professores da Educação Básica - Renafor. Universidade Federal de Pernambuco, Recife, 2013b.

PADILHA, M. A. S. e SANTANA, F. B. F. (2014). Sociedade digital e inclusão social: condições para uma educação digital. In: IX Seminário Internacional Exclusão Digital na Sociedade de Informação, 2015, Lisboa.

PRENSKY, M. Homo sapiens digital: dos imigrantes e nativos digitais à sabedoria digital. In: APARICI, R. (Coord.). Conectados no ciberespaço. São Paulo: Paulinas, 2012. 
SORJ, B. e GUEDES, L. E. Exclusão digital: problemas conceituais, evidências empíricas e políticas públicas. Novos estudos - CEBRAP. São Paulo, no 72, Jul, 2005. 